\title{
Ficus carica and Sizigium cumini Regulate Glucose and Lipid Parameters in High-Fat Diet and Streptozocin-Induced Rats
}

\author{
El-Shaimaa A. Arafa $\mathbb{D}^{1,2}$ Waseem Hassan ${ }^{1}{ }^{3}$, Ghulam Murtaza $^{(D)},^{3}$ \\ and Manal Ali Buabeid $\left(\mathbb{1}^{1}\right.$ \\ ${ }^{1}$ College of Pharmacy and Health Sciences, Ajman University, Ajman 346, UAE \\ ${ }^{2}$ Department of Pharmacology and Toxicology, Faculty of Pharmacy, Benisuef University, Beni-suef, 62514, Egypt \\ ${ }^{3}$ Department of Pharmacy, COMSATS University Islamabad, Lahore Campus, Lahore 54000, Pakistan \\ Correspondence should be addressed to Manal Ali Buabeid; m.buabeid@ajman.ac.ae
}

Received 18 July 2020; Revised 22 September 2020; Accepted 9 October 2020; Published 29 October 2020

Academic Editor: Secundino Cigarran

Copyright (c) 2020 El-Shaimaa A. Arafa et al. This is an open access article distributed under the Creative Commons Attribution License, which permits unrestricted use, distribution, and reproduction in any medium, provided the original work is properly cited.

\begin{abstract}
Obesity linked diabetes, popularly known as diabesity, has been viewed as a direct product of the modern lifestyle in both developed and developing countries, and its increased prevalence is seen as a major threat to public health globally. Ficus carica (FC) and Syzigium cumini (SC) are part of indigenous flora with traditional medicinal properties. Fresh seeds of SC fruit and fruit of FC were collected and macerated to obtain the final extract. Wistar rats were divided into seven groups fed either on a normal diet or high-fat diet (HFD) along with streptozocin (STZ) to induce diabesity. The crude extract of FC (FC.Cr.) and SC (SC.Cr.) were administered at $250 \mathrm{mg} / \mathrm{kg} / \mathrm{day}$ and $500 \mathrm{mg} / \mathrm{kg} / \mathrm{day}$ in induced diabesity state. Body weights, blood glucose level, complete blood count (CBC), cholesterol, triglycerides (TG), low-density lipoprotein (LDL), very-low-density lipoprotein (VLDL), and high-density lipoprotein (HDL) were recorded to analyze their effects on glucose and lipid metabolism. Further, superoxide dismutase (SOD) and malondialdehyde (MDA) were measured to examine their effects on lipid peroxidation and ant oxidative enzyme. Results showed that both FC.Cr. and SC.Cr. have the potential to control obesity-linked type 2 diabetes mellitus (T2DM) by lowering the body weights, serum glucose, cholesterol, TG, LDL, and VLDL, while increasing the protective effects of HDL dose-dependently. The crude extract of both plants showed significant activity to raise SOD and curb MDA under diabetic states. It was concluded that both FC.Cr. and SC.Cr. exhibited remarkable therapeutics potential in HFD-STZ-induced diabetic rats. However, we found that the effects of SC.Cr. are relatively more pronounced as compared to FC.Cr. in almost all parameters.
\end{abstract}

\section{Introduction}

The merger of obesity and diabetes led to the term "diabesity." Obesity causes gradual defects in insulin discharge along with increased insulin resistance (hyperinsulinemeia) which has the capacity to cause diabetes [1]. Obesity and type 2 diabetes mellitus (T2DM) are strongly interlinked and have a similar kind of pathophysiology [2]. The occurrence of obesity has reached the epidemic level all over the world. It is threatening globally, and many countries are facing the problem in its treatment, clinical management, and prevention [3]. Class II and class III obesity is directly linked with great danger to having diabetes. Women with obesity are at 10 times risk while obese men have 11.2 times more risk of developing diabetes [4]. The increased concurrence of obesity and diabetes compelled the World Health Organization (WHO) to state it as the "21st century epidemic." Furthermore, epidemiological studies have revealed that approximately $60-90 \%$ of patients with T2DM have been obese or overweight. It is potentially a predisposing factor in the late development of T2DM. Several research and studies proved that obesity is a robust risk factor to develop T2DM [5].

Interest in herbal therapies is increasing with the passage of time primarily due to the side effects of current therapeutic agents (oral hypoglycemic agents and insulin) used in diabetes mellitus. Many indigenous medicinal plants are useful to 
treat diabetes. Ficus carica Linn. (FC) is locally known as Anjeer or fig belongs to the family Moraceae [6]. It is generally found in tropical and subtropical regions of the world including the Indian subcontinent, southwest Asia, and Mediterranean regions. It is a plant with cultural and historic background, and its name is mentioned in traditional systems of medicine like Ayurveda, Unani, and Siddha [7, 8]. Its leaves, bark, tender shoots, fruits, seeds, and latex are used in traditional remedies such as antispasmodic, antipyretic, anthelmintic, antimutagenic, antioxidant, antifungal, hepatoprotective, and hypoglycemic agents [6,9]. In the context of this study, its hypolipidemic and hypoglycemic activities are reported in various diabetes-induced models [9-11]. The activities of FC are also reported in metabolic syndrome and related disorders [12]. Moreover, the protective effects of the FC leave on glucose and lipid metabolism along with the cytoprotective effects on pancreatic $\beta$-cells are described in the literature [13]. Badgujar et al. has prospectively termed FC as a potential pharmaceutical candidate which can be effective against anemia, cancer, diabetes, leprosy, liver diseases, paralysis, skin diseases, and ulcers [7]. In addition, its activities as anticancer [14], antimicrobial [15], and antiwarts agent [16] can also be found in the scientific literature. Its in vitro antiviral potential activity is described against herpes simplex type 1 (HSV-1), echovirus type 11 (ECV-11), and adenovirus (ADV). Authors argued that the hexanic and hexane-ethyl acetate extracts inhibited the multiplication of viruses at concentrations of $78 \mathrm{mg} / \mathrm{mL}[17,18]$.

Syzygium cumini (SC) is an eatable, commonly known as black plum which belongs to the family Myrtaceae. It contains a wide array of active biological constituents like gallic acid, anthocyanins, tannins, vitamin $\mathrm{C}$ includes cyanidin, petunidin, and malvi-din-glucoside among other substances [19]. It is commonly being widely used to treat diabetes by traditional practitioners over many centuries [20]. Its ripe fruits are used to prepare jams, jellies, squashes, and wine [21]. Studies have proved that methanol and ethyl acetate extracts of SC are effective in STZ-induced diabetes [22]. Further, its polyphenol-rich extract has shown pharmacological properties in restoring glucose tolerance and inducing insulin secretion [23]. In addition to antidiabetic properties, its pharmacological potential as antioxidative [24], antipyretic [25], anti-inflammatory [26], anticancer [27], antibacterial [27], and psychopharmacological [28] agent are documented in modern literature.

Thus, the aim of this study was to evaluate the antidiabetic, hypolipedmic, and antioxidant potentials of $F C$ and $S C$ in high-fat diet (HFD) and streptozocin (STZ-) induced diabetic rats. The antidiabesity effects of these two potential plants were compared with metformin.

\section{Materials and Methods}

2.1. Preparation of Extract. Whole fresh fruit of SC and FC were purchased from a local herbal store and identified according to the protocols. The plants were dried and macerated with $70 \%$ aqueous methanol. The filtrates were then evaporated in a rotary evaporator as standard procedures with slight modifications [29]. Crude extracts of FC (FC.Cr.) and SC (SC.Cr.) were freeze-dried and stored for further experimentation.

2.2. Experimental Animals and Measurement of Physical Parameters. STZ is appropriately mixed in the citrate buffer, and the calculated volume of solution is injected intraperitoneally in designated experimental rats. STZ has a dosedependent effect on $\beta$-cells; hence, its low dose of $30 \mathrm{mg} / \mathrm{kg} /$ day was used for 2 days [30] to induce T2DM like symptoms. Wistar rats weighing between $170-200 \mathrm{~g}$ were kept under standard environmental conditions of temperature $\left(25 \pm 2^{\circ} \mathrm{C}\right)$, relative humidity (50-55\%), and $12 / 12$ hours light and dark cycles. Animals were divided into seven groups each having six animals. The control group was fed on a normal diet, while the other six groups of rats were fed on HFD for 8 weeks. After three weeks, all groups, except the control group, were administered with a low dose of STZ for two days. Pharmacological intervention with FC.Cr. $(250 \mathrm{mg} / \mathrm{kg}$ and $500 \mathrm{mg} / \mathrm{kg})$ or SC.Cr. $(250 \mathrm{mg} / \mathrm{kg}$ and $500 \mathrm{mg} / \mathrm{kg}$ ) was then initiated in designated HFD/STZadministered groups. The plasma glucose level, body weight, food intake, and urine flow were measured periodically to monitor the induction of diabesity state and considered at the end of the study duration.

2.3. Measurement of Fasting Blood Glucose. For the monitoring of blood glucose levels, blood samples were collected by the tail cut method following standard methods [31]. The tail is cut with the help of sharp surgical scissors, and the tail is pressed to collect the blood on the wound-tip which is directly applied on the glucometer strip and measure the glucose level. The cut tail is wrapped in water-soaked cotton plug for at least 3-4 minutes to stop the unnecessary bleeding until the animal gets recovered from anesthesia.

2.4. Hematological Parameters. The blood sample was collected from the animals' eyes using nonheparinized capillary tubes, and hematological parameters were performed as per the reported procedure [32]. The determined parameters include platelet count, total leukocyte count, hemoglobin, WBCs, and RBCs.

2.5. Serum Lipid Analysis. After four weeks of the treatment, the animals were anaesthetized with a mixture of ketamine $(50 \mathrm{mg} / \mathrm{kg})$ and xylazine $(5 \mathrm{mg} / \mathrm{kg})$ i.p. The blood samples of all the animals of different groups were collected from cardiac puncture and separated by centrifugation at $5000 \mathrm{rpm}$ for fifteen minutes. Serum cholesterol, triglycerides (TG), high-density lipoprotein (HDL), very-low-density lipoprotein (VLDL), and low-density lipoprotein (LDL) were measured according to the methods recommended in respective kits [33].

2.6. Measurement of Serum Superoxide Dismutase (SOD). Serum was obtained from different experimental groups as per standard operation, and the analysis of SOD was carried out by commercially available kits according to the given protocols [33]. The absorbance was measured at $505 \mathrm{~nm}$ for SOD. The results were then calculated according to the manufacturer's instruction and expressed as units per milliliter. 


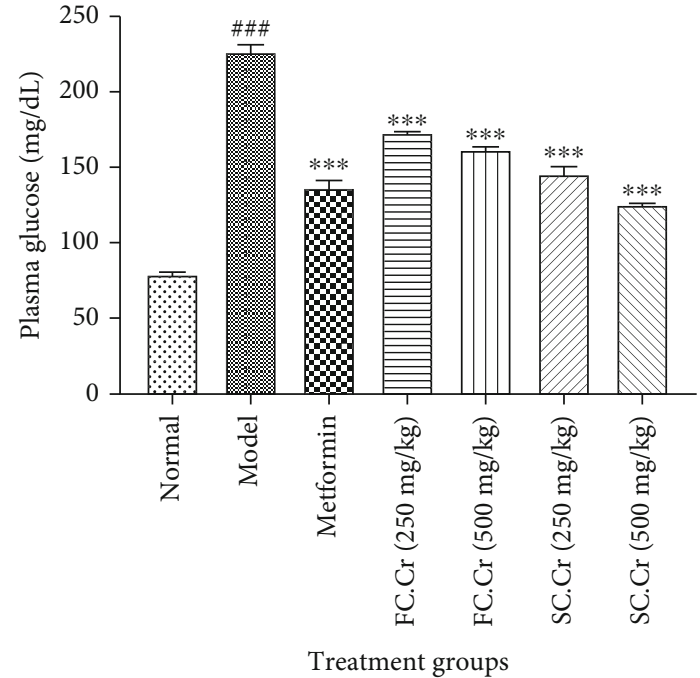

Figure 1: Graphical representation of fasting blood glucose level $(\mathrm{mg} / \mathrm{dL})$ after intervention with FC.Cr. and SC.Cr. in HFD-STZinduced rats. The fasting blood glucose level of FC.Cr. and SC.Cr. at doses $250 \mathrm{mg} / \mathrm{kg}$ and $500 \mathrm{mg} / \mathrm{kg}$ is compared with the standard drug metformin at the end of the study duration. The values are expressed as the mean of six animals in a group. Statistical analysis is performed with one-way ANOVA followed by Tukey's test. All the groups are compared with the HFD-STZ group, while the HFD-STZ group is compared with the normal group. The results are considered significant $\left({ }^{*}\right)$ if $P<0.05$ and $\left({ }^{* *}\right)$ if $P<0.01$ and highly significant $\left({ }^{* * *}\right)$ if $P<0.001$.

2.7. Determination of Lipid Peroxidation. Malondialdehyde (MDA) as a marker for lipid peroxidation was determined in serum by the double heating method of Draper and Hadley with some modifications. The principle of the method is based on the spectrophotometric measurement of the color produced during the reaction of TBA with MDA. For this purpose, $2.5 \mathrm{~mL}$ of $100 \mathrm{~g} / \mathrm{L}$ trichloroacetic acid solution was added into $0.5 \mathrm{~mL}$ serum in a centrifuge tube and placed in a boiling water bath for $15 \mathrm{~min}$. After cooling under tap water, the supernatant was transferred into a test tube containing $1 \mathrm{~mL}$ of $6.7 \mathrm{~g} / \mathrm{L}$ TBA solution and placed again in a boiling water bath for $15 \mathrm{~min}$. The solution was then cooled under tap water, and its absorbance was measured spectrophotometrically at $532 \mathrm{~nm}$ as per instructions [33]. The concentration of MDA was calculated using the following equation

$\operatorname{MDA}(\mathrm{nmoL} / \mathrm{mL})=(($ absorbance of sample/absorbance of standard) $\times 100)$.

2.8. Statistical Analysis. All results were shown as mean \pm SEM. The data interpretation was done through the statistical analysis "one-way analysis of variance (ANOVA)." The results were analyzed by using the Graph Pad Prism software version 5 . The significant effects were considered where $P<$ 0.05 .

\section{Results}

3.1. FC.Cr. and SC.Cr. Reverses HFD- and STZ-Induced Plasma Glucose. The level of plasma glucose remains a key

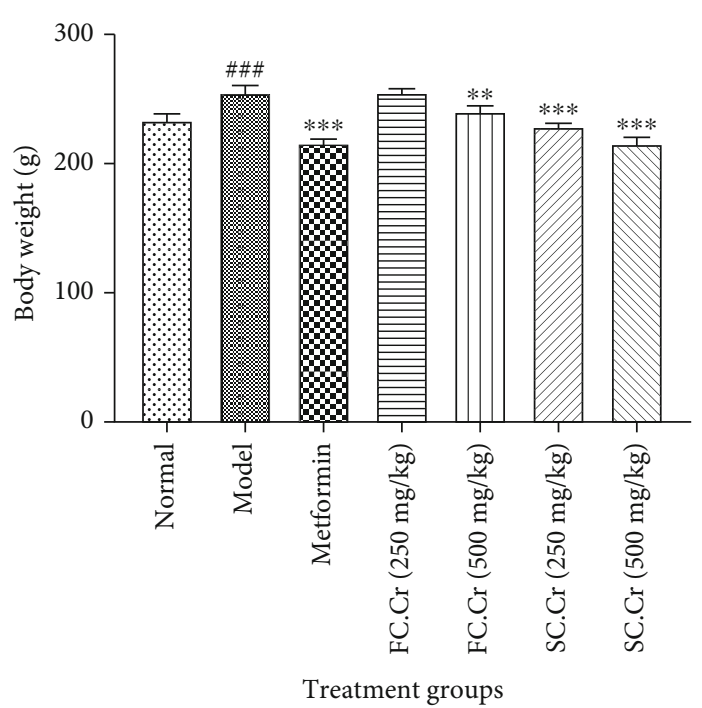

FIgure 2: Effects of FC.Cr. and SC.Cr. on body weights in HFDSTZ-induced rats with established diabesity. The rats were induced with HFD-STZ to mimic diabesity. FC.Cr. and SC.Cr. were administered at $250 \mathrm{mg} / \mathrm{kg}$ and $500 \mathrm{mg} / \mathrm{kg}$ after three weeks till the end of the study duration. Body weights were measured on a daily basis, and the final weights were compared with the standard drug metformin. The values are expressed as the mean of six animals in a group. Statistical analysis is performed with oneway ANOVA followed by Tukey's test. All the groups are compared with the HFD-STZ group, while the HFD-STZ group is compared with the normal group. The results are considered significant $\left(^{*}\right)$ if $P<0.05\left(^{* *}\right)$ and if $P<0.01$ and highly significant $\left({ }^{* * *}\right)$ if $P<0.001$.

prognostic factor in the diagnosis of diabetes. Our results manifested that the administration of STZ along with HFD robustly increased the fasting plasma glucose level, and the trend continued till the end of the study duration. The intervention by FC.Cr. showed a significant dose-dependent reduction in plasma glucose levels as it was recorded at 165 $\pm 5 \mathrm{mg} / \mathrm{dL}$ at $250 \mathrm{mg} / \mathrm{kg}$ and $150 \pm 5 \mathrm{mg} / \mathrm{dL}$ at $500 \mathrm{mg} / \mathrm{kg}$. Similarly, the plasma glucose levels were $140 \pm 5 \mathrm{mg} / \mathrm{dL}$ and $120 \pm 5 \mathrm{mg} / \mathrm{dL}$ at $250 \mathrm{mg} / \mathrm{kg}$ and $500 \mathrm{mg} / \mathrm{kg}$ of SC.Cr., respectively. It was interesting to notice that the effects of SC.Cr. were more pronounced in controlling plasma glucose as compared to FC.Cr. (Figure 1).

3.2. Effects of FC.Cr. and SC.Cr. on Body Weights. A relatively notable increase in the body weights of animals fed on STZ along with HFD was recorded. It was noted that the increase in the body weights was not overwhelming in terms of grams as was recorded by other studies feeding animals on HFD alone [34]. The effects of FC.Cr. on body weights were unremarkable, especially at $250 \mathrm{mg} / \mathrm{kg}$, but SC.Cr. at both low $(250 \mathrm{mg} / \mathrm{kg})$ and high dose $(500 \mathrm{mg} / \mathrm{kg})$ was able to decrease the body weight to some extent. Metformin was used as a standard drug, which is well known to reduce body weights [35]. Interestingly, the ability of SC.Cr. at a higher dose to reduce the body weights was similar to that of metformin (Figure 2). 
TABLE 1: Complete blood count (CBC) of the experimental animals.

\begin{tabular}{|c|c|c|c|c|}
\hline Groups & Red blood cells $\left(10^{6 /} \mathrm{UL}\right)$ & White blood cells $\left(10^{3} / \mathrm{UL}\right)$ & Platelets $\left(10^{3} / \mathrm{UL}\right)$ & Hemoglobin $(\mathrm{g} / \mathrm{dL})$ \\
\hline Normal & $7.5 \pm 0.25$ & $7.0 \pm 0.086^{* * *}$ & $942 \pm 11$ & $13 \pm 0.26$ \\
\hline HFD-STZ & $7.9 \pm 0.15$ & $13 \pm 0.21$ & $740 \pm 54$ & $13 \pm 0.10$ \\
\hline Metformin $(500 \mathrm{mg} / \mathrm{kg})$ & $7.3 \pm 0.19$ & $11 \pm 0.61$ & $942 \pm 68$ & $13 \pm 0.067$ \\
\hline FC.Cr. $(250 \mathrm{mg} / \mathrm{kg})$ & $8.4 \pm 0.14$ & $8.9 \pm 0.66^{* * *}$ & $850 \pm 27$ & $13 \pm 0.088$ \\
\hline FC.Cr. (500 mg/kg) & $8.3 \pm 0.11$ & $8.1 \pm 0.53^{* * *}$ & $882 \pm 98$ & $12 \pm 0.50$ \\
\hline SC.Cr. $(250$ mg/kg) & $8.2 \pm 0.20$ & $11 \pm 0.34^{* *}$ & $879 \pm 46$ & $13 \pm 0.10$ \\
\hline SC.Cr. (500 mg/kg) & $8.0 \pm 0.49$ & $8.0 \pm 0.38^{* * *}$ & $822 \pm 107$ & $13 \pm 0.25$ \\
\hline
\end{tabular}

Data values are shown as mean \pm SEM of 6 animals in each group. The results are evaluated by using the one way ANOVA then compared with the HFD-STZ group. The results are significant is $P<0.05\left(^{*}\right)$, more significant $\left({ }^{* *}\right)$ if $P<0.01$, and highly significant $\left({ }^{* * *}\right)$ if $P<0.001$.

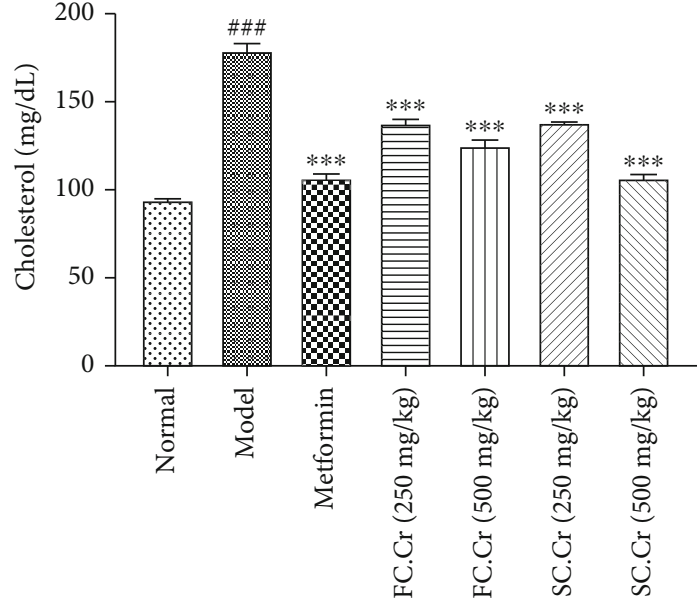

Treatment groups

(a)

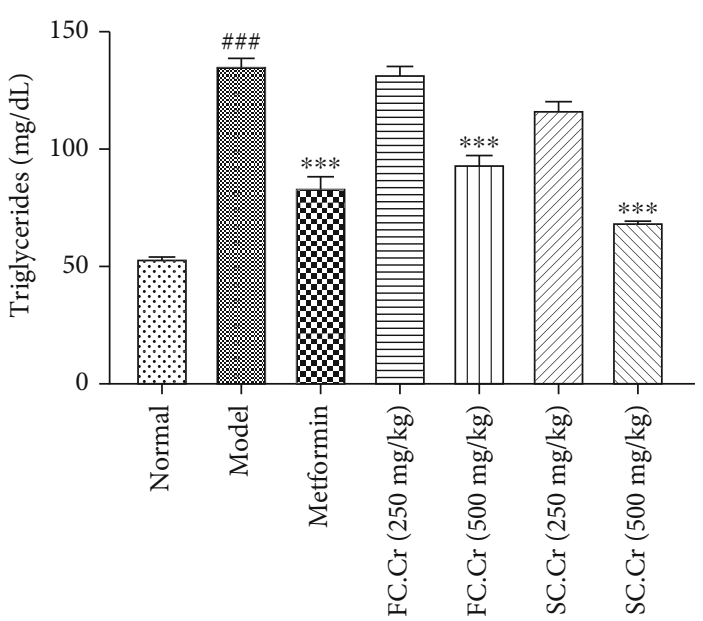

Treatment groups

(b)

FIGURE 3: Effects of FC.Cr. and SC.Cr. on plasma levels of cholesterol (mg/dL) and TG (mg/dL) in HFD-STZ-induced rats. FC.Cr. and SC.Cr. were administered at $250 \mathrm{mg} / \mathrm{kg}$ and $500 \mathrm{mg} / \mathrm{kg}$ after three weeks till the end of study duration. Cholesterol (a) and TG (b) were measured after drawing plasma from the treated and normal group of rats. The values are expressed as the mean of six animals in a group. Statistical analysis is performed with one-way ANOVA followed by Tukey's test. All the groups are compared with the HFD-STZ group, while the HFD-STZ group is compared with the normal group. Results are considered significant $\left({ }^{*}\right)$ if $P<0.05\left({ }^{* *}\right)$ and if $P<0.01$ and highly significant $\left({ }^{* *}\right)$ if $P<0.001$.

3.3. Effects of FC.Cr. and SC.Cr. on Complete Blood Count $(C B C)$. Blood was collected in test tubes already containing EDTA to avoid the coagulation of blood. The CBC results are tabulated in Table 1. Red blood cells, white blood cells, platelets, and hemoglobin are measured. There was no noticeable change recorded on hemoglobin, $\mathrm{RBC}$, and platelet count; however, expectedly, a significant increase was observed in WBC count as obesity is linked with the lowgrade inflammation [36, 37]. FC.Cr. at $250 \mathrm{mg} / \mathrm{kg}$ reduced the WBs to $8.9 \pm 0.66\left(10^{3} / \mathrm{UL}\right)$ and to $8.1 \pm 0.53\left(10^{3} / \mathrm{UL}\right)$ at $500 \mathrm{mg} / \mathrm{kg}$. Similarly, SC.Cr. decreased the WBs to $11 \pm$ $0.34\left(10^{3} / \mathrm{UL}\right)$ and $8.0 \pm 0.38\left(10^{3} / \mathrm{UL}\right)$ at $250 \mathrm{mg} / \mathrm{kg}$ and $500 \mathrm{mg} / \mathrm{kg}$, respectively, as compared to the HFD-STZ group which was recorded at $13 \pm 0.21\left(10^{3} / \mathrm{UL}\right)$.

3.4. FC.Cr. and SC.Cr. Improves the Plasma Lipid Profile in Diabesity. All major parameters of serum lipid profile (TC, TG, LDL, HDL, and VLDL) were measured to analyze the lipid metabolic activities of FC.Cr. and SC.Cr. Raised levels of plasma cholesterol induced by HFD and STZ were significantly brought back by FC.Cr. and SC.Cr.; however, the relative control by SC.Cr. at $250 \mathrm{mg} / \mathrm{kg}(140 \pm 5 \mathrm{mg} / \mathrm{dL})$ and $500 \mathrm{mg} / \mathrm{kg}(130 \pm 5 \mathrm{mg} / \mathrm{dL})$ was relatively more significant as compared to FC.Cr. at $250 \mathrm{mg} / \mathrm{kg}(140 \pm 5 \mathrm{mg} / \mathrm{dL})$ and $500 \pm 5 \mathrm{mg} / \mathrm{kg}(100 \pm 5 \mathrm{mg} / \mathrm{dL})$ (Figure 3(a)). A similar pattern of control was observed in the TG level, where SC.Cr. at $500 \pm 5 \mathrm{mg} / \mathrm{kg}$ was found more effective as compared to FC.Cr. at similar doses (Figure 3(b)). The relative TG control difference was also obvious at $250 \mathrm{mg} / \mathrm{kg}(135 \pm 5 \mathrm{mg} / \mathrm{dL}$ compared to $115 \pm 5 \mathrm{mg} / \mathrm{dL}$ ) dose of both SC.Cr. and FC.Cr. Similarly, the plasma level of HDL, which was suppressed in the HFD and STZ administered group was remarkably and dose-dependently restored by FC.Cr. and SC.Cr. Likewise, the amount of control with SC.Cr. at $250 \mathrm{mg} / \mathrm{kg}$ and $500 \mathrm{mg} / \mathrm{kg}$ was better than FC.Cr. at $250 \mathrm{mg} / \mathrm{kg}$ and $500 \mathrm{mg} / \mathrm{kg}$ doses (Figure 4(a)). Finally, the plasma levels of 


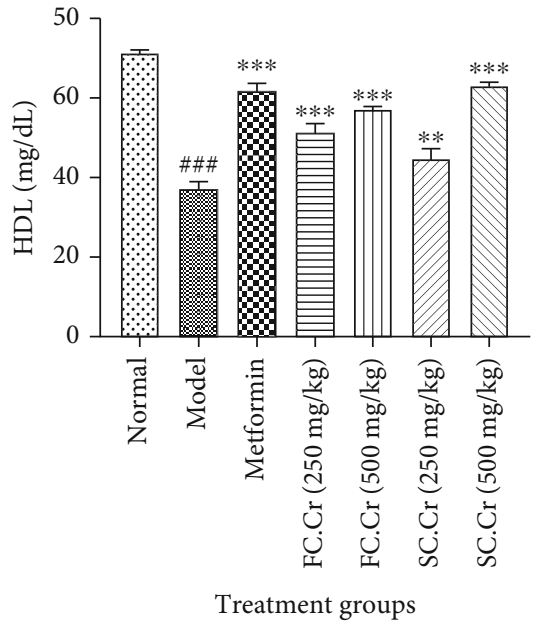

(a)

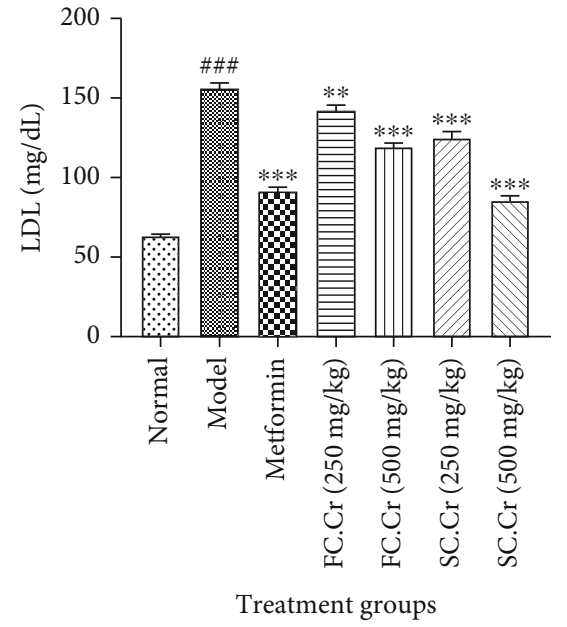

(b)

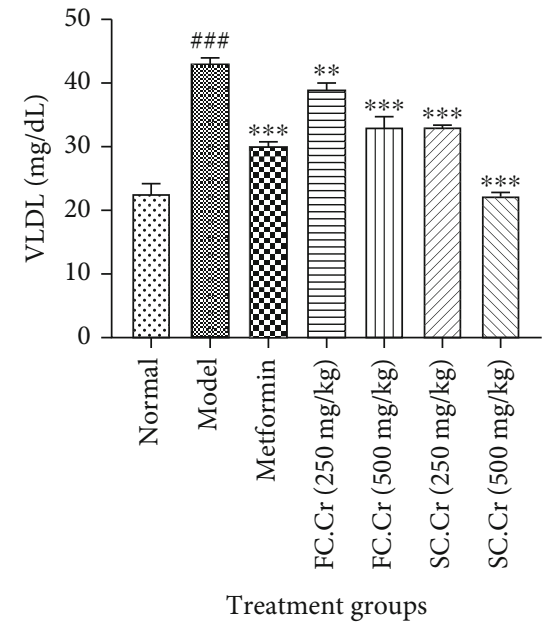

(c)

Figure 4: Effects of FC.Cr. and SC.Cr. on plasma levels of HDL (mg/dL), LDL (mg/dL), and VLDL (mg/dL) in HFD-STZ-induced rats. FC.Cr. and SC.Cr. were administered at $250 \mathrm{mg} / \mathrm{kg}$ and $500 \mathrm{mg} / \mathrm{kg}$ after three weeks till the end of study duration. HDL (a), LDL (b), and VLDL (c) were measured after drawing plasma from the treated and normal group of rats. The values are expressed as the mean of six animals in a group. Statistical analysis is performed with one-way ANOVA followed by Tukey's test. All the groups are compared with the HFD-STZ group, while the HFD-STZ group is compared with the normal group. The results are considered significant $\left(^{*}\right)$ if $P<0.05$ and $\left({ }^{* *}\right)$ if $P<0.01$ and highly significant $\left({ }^{* * *}\right)$ if $P<0.001$.

LDL and VLDL were decreased when FC.Cr. and SC.Cr. were administered in the presence of HFD and STZ. The LDL and VLDL levels at the doses of $250 \mathrm{mg} / \mathrm{kg}$ and $500 \mathrm{mg} / \mathrm{kg}$ of FC.Cr. and SC.Cr. showed comparative results in which the effects of SC.Cr. at both doses were superseded as compared to that of FC.Cr. (Figures 4(b), 4(C)).

3.5. FC.Cr. and SC.Cr. Ameliorate SOD and MDA. The plasma level of SOD was significantly curtailed in the diabesity-induced group. The level was favorably brought to normal in a significant and dose-dependent manner with the administration of FC.Cr. and SC.Cr. (Figure 5(a)). FC.Cr. at $250 \mathrm{mg} / \mathrm{kg}$ and $500 \mathrm{mg} / \mathrm{kg}$ brought the SOD levels up to $96 \pm 5 \mathrm{U} / \mathrm{mL}$ and $115 \pm 5 \mathrm{U} / \mathrm{mL}$, respectively. Similarly, SC.Cr. raised the level of SOD to $125 \pm 5 \mathrm{U} / \mathrm{mL}$ and $155 \pm 5$ $\mathrm{U} / \mathrm{mL}$ when administered at the doses of $250 \mathrm{mg} / \mathrm{kg}$ and $500 \mathrm{mg} / \mathrm{kg}$, respectively. The dose comparison of both plants at equivalent doses shows the superior effects of SC.Cr. on SOD. Similarly, both FC.Cr. and SC.Cr. considerably reduced the raised levels of MDA at $250 \mathrm{mg} / \mathrm{kg}$ and $500 \mathrm{mg} / \mathrm{kg}$ (Figure 5(b)). It was noticed that the effects of SC.Cr. at both comparative doses surpassed the FC.Cr. effects.

\section{Discussion}

Diabesity has been turned into a major clinical issue all over the globe as a result of modern lifestyle adaptations and complex dietary habits. It is a term that has been coined to cover the interface of obesity and diabetes. Data in the past two decades have revealed that obesity is one of the major risk factors of diabetes $[38,39]$. The presence of diabetes in obese individuals complicates the overall metabolic scenario in the body that has a potential to develop into metabolic syndrome and cardiovascular complications [40, 41]. As most of the scientific efforts are concentrated towards finding an isolated treatment for diabetes or obesity, only a handful of studies highlight the combined treatment options for both diabetes and obesity. However, in modern times, diabesity has achieved a significant attention from medical professionals and researchers, owing to its increasing prevalence worldwide. The prevalence of diabesity is drastically affecting the working efficiency and lifestyle of the obese people.

The herbal method of treatment remains a cornerstone of therapeutics. Medicinal plants have been used for centuries to treat diabetes and obesity. This study aimed to use two medicinally active plants in diabesity with a significantly established metabolic profile. The plants were selected through a literature survey and evaluation of their potential as pharmacological agents. The FC.Cr. fruit is rich in sugars, minerals, phenolic mixtures, and vitamins. It has high contents of polyphenols and amino acids. Its components are free of fat and cholesterol [42]. Similarly, the methanolic extract of seeds of SC.Cr. has different phytochemicals which are effective in different diseases. The presence of glycosides, flavonoids, and tannins with alkaloids helps lower the blood glucose level. Similarly, saponins are reported to decrease cholesterol [43].

Diabesity animal models are considered as a useful method for the investigation of newer antidiabetic drugs. As human diabetic clinical conditions involve the features of insulin resistance, $\beta$-cell deficiency, and consistent hyperglycemia, the diabesity models seem to serve the purpose. STZ, 2-deoxy-2-(3-(methyl-3-nitrosoureido)-D-glucopyranose) is known to induce type 1 and T2DM in rats [44]. Recently, HFD/STZ-induced rodent diabetic models have gain popularity due to their relative ability to mimic the state of obesity along with diabetes depending upon the length of HFD administration [30]. Usually, 8 weeks of HFD/STZ model produce significant symptoms of hyperglycemia and hyperlipidemia [45]. Keeping in mind all these factors, we 


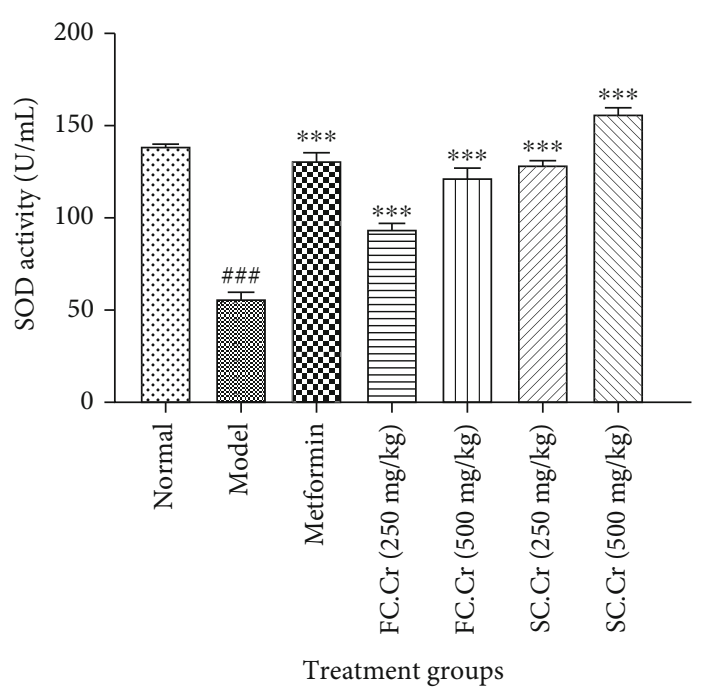

(a)

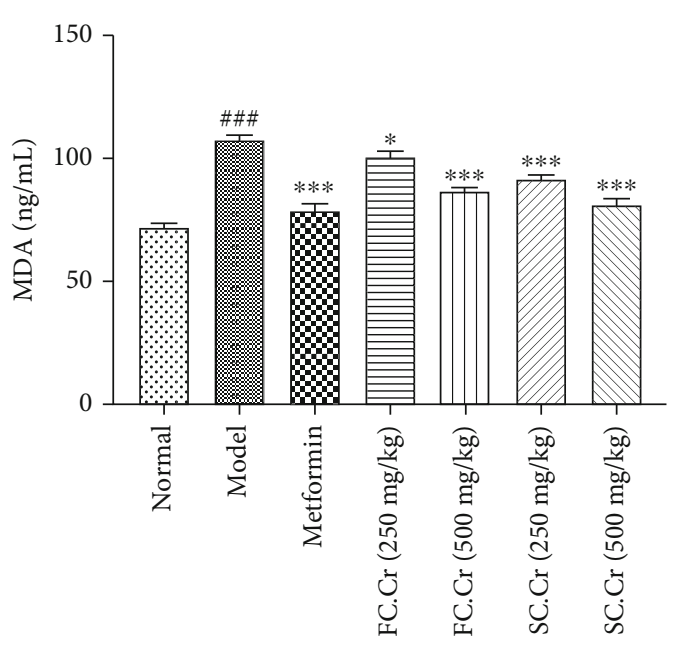

Treatment groups

(b)

FIGURE 5: Effects of FC.Cr. and SC.Cr. on plasma levels of SOD $(\mathrm{U} / \mathrm{mL})$ and MDA $(\mathrm{ng} / \mathrm{mL})$ in HFD-STZ-induced rats. FC.Cr. and SC.Cr. were administered at $250 \mathrm{mg} / \mathrm{kg}$ and $500 \mathrm{mg} / \mathrm{kg}$ after three weeks till the end of study duration. SOD (a) and MDA (b) were measured after drawing plasma from the treated and normal group of rats. The values are expressed as the mean of six animals in a group. Statistical analysis is performed with one-way ANOVA followed by Tukey's test. All the groups are compared with the HFD-STZ group, while the HFD-STZ group is compared with the normal group. Results are considered significant $\left({ }^{*}\right)$ if $P<0.05,\left({ }^{* *}\right)$ and if $P<0.01$ and highly significant $\left({ }^{* * *}\right)$ if $P<0.001$.

selected the HFD/STZ-induced model for 8 weeks in rats with slight modifications [46]. In our study, the diabesity model was successfully established that exhibited a significant increase in fasting blood glucose levels compared to normal rats which signifies insulin resistance/insufficient insulin release. Similarly, body weights were also monitored during study duration, which was found to notably increase in the HFD/STZ group. However, we noticed that the even significant increase in body weights of the HFD/STZ group was far lesser in terms of the number of grams increase where alone HFD was administered for a similar duration [47]. This can be due to the fact that STZ curbs the increase in body weights generally as recorded in previous studies $[48,49]$.

The pharmacological intervention with FC.Cr. and SC.Cr. in HFD/STZ-induced diabesity remarkably improved the morbid state. Both FC.Cr. and SC.Cr. reduced the increase in body weights, but a reduction was more pronounced with SC.Cr. as compared to FC.Cr. which even showed a nonsignificant decrease in body weights at $250 \mathrm{mg} / \mathrm{kg}$ of dose. Similarly, FBG was also curtailed by both extracts, but the extent of reduction of SC.Cr. surpassed FC.Cr. The decrease in body weights along with FBG the decline encouraged us to analyze the effects of FC.Cr. and SC.Cr. on lipid profile. It was noted that both FC.Cr. and SC.Cr. extraordinarily improve the HFD/STZ dysregulated plasma lipid profile. Despite the fact that both showed significant results, yet SC.Cr. exhibited a superior improvement in lipid profile as compared to FC.Cr. Further, we compared the finding of FC.Cr. and SC.Cr. at $250 \mathrm{mg} / \mathrm{kg}$ and found that the latter was more effective in lowering LDL, VLDL, TG, and cholesterol even at a lower dose. The pattern of plasma lipid control was more pronounced at $500 \mathrm{mg} / \mathrm{kg}$ in favor of SC.Cr.
Oxidative stress plays a vital role in both diabetes and obesity [50-52]. It is also well established that the raised oxidative stress is associated with increasing the risk factors of diabetes such as altering pancreatic insulin secretion and the effects of the hormone on target cells [53]. SOD is a major antioxidative enzyme which plays a pivotal role in the neutralization of reactive oxygen species (ROS) $[54,55]$ and lowers oxidative stress. We have found that both FC.Cr. and SC.Cr. increase the level of SOD in plasma. Similarly, MDA are the product of lipid peroxidation [56]. The effects of SC.Cr on SOD and MDA at both $250 \mathrm{mg} / \mathrm{kg}$ and $500 \mathrm{mg} / \mathrm{kg}$ were more significant as compared to FC.Cr. at both doses. Previous studies have shown that the concentration of MDA is increased in diabetes mellitus [57]. Early changes of collagen by sugar adducts that form a series of glycation products incite the degradation of the lipids to MDA and hence further cross-linking by MDA of the already modified collagen. We found that both FC.Cr. and SC.Cr. decrease the MDA to a considerable extent while the effects of SC.Cr. remained superior to FC.Cr.

It can be concluded that both FC.Cr. and SC.Cr. are effective in obesity-linked diabetes by regulating the various glucose, lipid metabolic products, and oxidative stress factors. The effects of SC.Cr. are found to be more prominent in all measured parameters. Further studies are required to clarify the exact mechanism of both plants.

\section{Data Availability}

The data used to support the findings of this study are available from the corresponding author upon request. 


\section{Conflicts of Interest}

The authors declare that there are no conflicts of interest.

\section{Acknowledgments}

We would like to thank our entire laboratory staff at COMSATS University Islamabad, Lahore campus, for helping at various stages of the study. The study was supported by the College of Pharmacy and Health Sciences, Ajman University, Ajman, United Arab Emirates.

\section{References}

[1] C. Stalin, P. Dineshkumar, and K. Nithiyananthan, "Evaluation of antidiabetic activity of methanolic leaf extract of ficus carica in alloxan - induced diabetic rats," Asian Journal of Pharmaceutical and Clinical Research, vol. 5, no. 3, pp. 8587, 2012.

[2] C. J. Bailey, "Drugs on the horizon for diabesity," Current Diabetes Reports, vol. 5, no. 5, pp. 353-359, 2005.

[3] R. A. DeFronzo, R. Gunnarsson, O. Björkman, M. Olsson, and J. Wahren, "Effects of insulin on peripheral and splanchnic glucose metabolism in noninsulin-dependent (type II) diabetes mellitus," The Journal of Clinical Investigation, vol. 76, no. 1, pp. 149-155, 1985.

[4] A. E. Field, E. H. Coakley, A. Must et al., "Impact of overweight on the risk of developing common chronic diseases during a 10-year period," Archives of Internal Medicine, vol. 161, no. 13, pp. 1581-1586, 2001.

[5] A. Golay and J. Ybarra, "Link between obesity and type 2 diabetes," Best Practice \& Research Clinical Endocrinology \& Metabolism, vol. 19, no. 4, pp. 649-663, 2005.

[6] S. S. Irudayaraj, A. Stalin, C. Sunil, V. Duraipandiyan, N. A. alDhabi, and S. Ignacimuthu, "Antioxidant, antilipidemic and antidiabetic effects of ficusin with their effects on GLUT4 translocation and PPAR $\gamma$ expression in type 2 diabetic rats," Chemico-Biological Interactions, vol. 256, pp. 85-93, 2016.

[7] S. B. Badgujar, V. V. Patel, A. H. Bandivdekar, and R. T. Mahajan, "Traditional uses, phytochemistry and pharmacology of Ficus carica: a review," Pharmaceutical Biology, vol. 52, no. 11, pp. 1487-1503, 2014.

[8] P. V. V. Prasad, P. K. J. P. Subhaktha, A. Narayana, and M. M. Rao, "Medico-historical study of "aśvattha" (sacred fig tree)," Bulletin of the Indian Institute of History of Medicine (Hyderabad), vol. 36, no. 1, pp. 1-20, 2006.

[9] J. R. Canal, M. D. Torres, A. Romero, and C. Pérez, “A chloroform extract obtained from a decoction of Ficus carica leaves improves the cholesterolaemic status of rats with streptozotocin-induced diabetes," Acta Physiologica Hungarica, vol. 87, no. 1, pp. 71-76, 2000.

[10] S. Mawa, K. Husain, and I. Jantan, "Ficus carica L. (Moraceae): phytochemistry, traditional uses and biological activities," Evidence-based Complementary and Alternative Medicine, vol. 2013, 8 pages, 2013.

[11] C. Pérez, E. Domínguez, J. M. Ramiro, A. Romero, J. E. Campillo, and M. D. Torres, "A study on the glycaemic balance in streptozotocin-diabetic rats treated with an aqueous extract of Ficus carica (fig tree) leaves," Phytotherapy Research, vol. 10, no. 1, pp. 82-83, 1996.
[12] L. Joerin, M. Kauschka, B. Bonnländer, I. Pischel, B. Benedek, and V. Butterweck, "Ficus carica leaf extract modulates the lipid profile of rats fed with a high-fat diet through an increase of HDL-C," Phytotherapy Research, vol. 28, no. 2, pp. 261-267, 2014.

[13] S. Stephen Irudayaraj, S. Christudas, S. Antony, V. Duraipandiyan, A. D. Naif Abdullah, and S. Ignacimuthu, "Protective effects of Ficus carica leaves on glucose and lipids levels, carbohydrate metabolism enzymes and $\beta$-cells in type 2 diabetic rats," Pharmaceutical Biology, vol. 55, no. 1, pp. 1074-1081, 2017.

[14] S. Rubnov, Y. Kashman, R. Rabinowitz, M. Schlesinger, and R. Mechoulam, "Suppressors of cancer cell proliferation from fig (Ficus carica) resin: isolation and structure elucidation," Journal of Natural Products, vol. 64, no. 7, pp. 993-996, 2001.

[15] H. L. Aref, K. B. Salah, J. P. Chaumont, A. Fekih, M. Aouni, and K. Said, "In vitro antimicrobial activity of four Ficus carica latex fractions against resistant human pathogens (antimicrobial activity of Ficus carica latex)," Pakistan Journal of Pharmaceutical Sciences, vol. 23, no. 1, pp. 53-58, 2010.

[16] S. Bohlooli, A. Mohebipoor, S. Mohammadi, M. Kouhnavard, and S. Pashapoor, "Comparative study of fig tree efficacy in the treatment of common warts (Verruca vulgaris) vs. cryotherapy," International Journal of Dermatology, vol. 46, no. 5, pp. 524-526, 2007.

[17] H. Lazreg Aref, B. Gaaliche, A. Fekih et al., "In vitro cytotoxic and antiviral activities of Ficus carica latex extracts," Natural Product Research, vol. 25, no. 3, pp. 310-319, 2011.

[18] H. L. Aref, H. Mosbah, H. Louati, K. Said, and B. Selmi, "Partial characterization of a novel amylase activity isolated from Tunisian Ficus carica latex," Pharmaceutical Biology, vol. 49, no. 11, pp. 1158-1166, 2011.

[19] C. A. Martinez, M. E. Loureiro, M. A. Oliva, and M. Maestri, "Differential responses of superoxide dismutase in freezing resistant Solanum curtilobum and freezing sensitive Solanum tuberosum subjected to oxidative and water stress," Plant Science, vol. 160, no. 3, pp. 505-515, 2001.

[20] N. Rekha, R. Balaji, and M. Deecaraman, "Effect of aqueous extract of Syzygium cumini pulp on antioxidant defense system in streptozotocin induced diabetic rats," Iranian Journal of Pharmacology and Therapeutics, vol. 7, no. 2, p. 137, 2008.

[21] P. S. Prince, N. Kamalakkannan, and V. P. Menon, “Antidiabetic and antihyperlipidaemic effect of alcoholic Syzigium cumini seeds in alloxan induced diabetic albino rats," Journal of Ethnopharmacology, vol. 91, no. 2-3, pp. 209-213, 2004.

[22] J. Shinde, T. Taldone, M. Barletta et al., "Alpha-glucosidase inhibitory activity of Syzygium cumini (Linn.) Skeels seed kernel in vitro and in Goto-Kakizaki (GK) rats," Carbohydrate Research, vol. 343, no. 7, pp. 1278-1281, 2008.

[23] J. R. Sanches, L. M. França, V. T. Chagas et al., "Polyphenolrich extract of Syzygium cumini leaf dually improves peripheral insulin sensitivity and pancreatic islet function in monosodium L-glutamate-induced obese rats," Frontiers in Pharmacology, vol. 7, 2016.

[24] P. S. M. Prince and V. P. Menon, "Effect of Syzigium cumini in Plasma Antioxidants on Alloxan-Induced Diabetes in Rats," Journal of Clinical Biochemistry and Nutrition, vol. 25, no. 2, pp. 81-86, 1998.

[25] P. K. Mahapatra, D. Chakraborty, and A. K. Chaudhuri, "Antiinflammatory and antipyretic activities of Syzygium cuminii," Planta Medica, vol. 52, no. 6, 1986. 
[26] A. K. N. Chaudhuri, S. Pal, A. Gomes, and S. Bhattacharya, "Anti-inflammatory and related actions of Syzygium cuminii seed extract," Phytotherapy Research, vol. 4, no. 1, pp. 5-10, 1990.

[27] S. S. Yadav, G. Meshram, D. Shinde, R. Patil, S. M. Manohar, and M. V. Upadhye, "Antibacterial and anticancer activity of bioactive fraction of Syzygium cumini L. Seeds," HAYATI Journal of Biosciences, vol. 18, no. 3, pp. 118122, 2011.

[28] D. Chakraborty, P. Mahapatra, and A. Nag Chaudhuri, Studies on Psychopharmacological Actions of Syzygium Cuminii Linn. Seed Extract, vol. 13, no. 7-8, 1985IRCS Medical Science: Psychology \& Psychiatry, 1985

[29] E. A. Arafa, M. A. Buabeid, W. Hassan, G. Murtaza, T. A. Chohan, and H. Ahmed, "Protective effects of Cocos nucifera oil in Paraphenylene diamine toxicity," Current Pharmaceutical Biotechnology, vol. 21, 2020.

[30] S. Skovsø, "Modeling type 2 diabetes in rats using high fat diet and streptozotocin," Journal of Diabetes Investigation, vol. 5, no. 4, pp. 349-358, 2014.

[31] Z. Tahergorabi, H. Rahmani, J. Williams, and M. Moodi, “The effect of methadone on blood glucose, lipids and glucosemodulating hormones in methadone-dependent Wistar rats," Toxicology Research, vol. 36, no. 3, pp. 221-226, 2020.

[32] A. S. Qureshi, J. Ghaffor, M. Usman, N. Ehsan, Z. Umar, and A. Sarfraz, "Effect of ethanolic preparations of cinnamon (Cinnamomum zeylanicum) extract on hematologic and histometric parameters of selected organs in Alloxan $\left({ }^{\circledR}\right)$ induced diabetic female albino rats," Journal of Diabetes and Metabolic Disorders, vol. 18, no. 2, pp. 505-512, 2019.

[33] W. Hassan, G. Rongyin, A. Daoud et al., "Reduced oxidative stress contributes to the lipid lowering effects of isoquercitrin in free fatty acids induced hepatocytes," Oxidative Medicine and Cellular Longevity, vol. 2014, Article ID 313602, 18 pages, 2014.

[34] G. Qin, J. Ma, Q. Huang et al., "Isoquercetin improves hepatic lipid accumulation by activating AMPK pathway and suppressing TGF- $\beta$ signaling on an HFD-induced nonalcoholic fatty liver disease rat model," International Journal of Molecular Sciences, vol. 19, no. 12, 2018.

[35] R. Pu, D. Shi, T. Gan et al., "Effects of metformin in obesity treatment in different populations: a meta-analysis," Therapeutic Advances in Endocrinology and Metabolism, vol. 11, p. 204201882092600, 2020.

[36] R. A. DeFronzo, "The triumvirate: cell, muscle, liver: a collusion responsible for NIDDM," Diabetes, vol. 37, no. 6, pp. 667-687, 1988.

[37] P. Mohanty, W. Hamouda, R. Garg, A. Aljada, H. Ghanim, and P. Dandona, "Glucose challenge stimulates reactive oxygen species (ROS) generation by leucocytes," The Journal of Clinical Endocrinology \& Metabolism, vol. 85, no. 8, pp. 2970-2973, 2000.

[38] A. Volaco, A. M. Cavalcanti, R. P. Filho, and D. B. Precoma, "Socioeconomic status: the missing link between obesity and diabetes mellitus?," Current Diabetes Reviews, vol. 14, no. 4, pp. 321-326, 2018.

[39] D. R. Leitner, G. Frühbeck, V. Yumuk et al., "Obesity and type 2 diabetes: two diseases with a need for combined treatment strategies - EASO can Lead the way," Obesity Facts, vol. 10, no. 5, pp. 483-492, 2017.
[40] A. F. Cicero and A. Colletti, "Role of phytochemicals in the management of metabolic syndrome," Phytomedicine, vol. 23, no. 11, pp. 1134-1144, 2016.

[41] B. Kumari and U. C. S. Yadav, "Adipokine Visfatin's role in pathogenesis of diabesity and related metabolic derangements," Current Molecular Medicine, vol. 18, no. 2, pp. 116125, 2018.

[42] S. M. Neha Soni, G. Satpathy, and R. K. Gupta, "Estimation of nutritional, phytochemical, antioxidant and antibacterial activity of dried fig (Ficus carica)," Journal of Pharmacognosy and Phytochemistry, vol. 3, no. 2, pp. 158-165, 2014.

[43] A. Kumar, R. Ilavarasan, T. Jayachandran et al., "Phytochemicals investigation on a tropical plant, Syzygium cumini from Kattuppalayam, Erode district, Tamil Nadu, South India," Pakistan Journal of Nutrition, vol. 8, no. 1, pp. 83-85, 2009.

[44] S. Bathina, N. Srinivas, and U. N. Das, "BDNF protects pancreatic $\beta$ cells (RIN5F) against cytotoxic action of alloxan, streptozotocin, doxorubicin and benzo(a)pyrene in vitro," Metabolism, vol. 65, no. 5, pp. 667-684, 2016.

[45] X. X. Guo, Y. Wang, K. Wang, B. P. Ji, and F. Zhou, "Stability of a type 2 diabetes rat model induced by high-fat diet feeding with low-dose streptozotocin injection," Journal of Zhejiang University. Science. B, vol. 19, no. 7, pp. 559-569, 2018.

[46] V. P. Veerapur, K. R. Prabhakar, B. S. Thippeswamy, P. Bansal, K. K. Srinivasan, and M. K. Unnikrishnan, "Antidiabetic effect of Ficus racemosa Linn. Stem bark in high-fat diet and lowdose streptozotocin-induced type 2 diabetic rats: a mechanistic study," Food Chemistry, vol. 132, no. 1, pp. 186-193, 2012.

[47] X. Q. Yang, H. Yuan, J. Li et al., "Swimming intervention mitigates HFD-induced obesity of rats through PGC- $1 \alpha$-irisin pathway," European Review for Medical and Pharmacological Sciences, vol. 20, no. 10, pp. 2123-2130, 2016.

[48] P. T. Yeh, H. W. Huang, C. M. Yang, W. S. Yang, and C. H. Yang, "Astaxanthin inhibits expression of retinal oxidative stress and inflammatory mediators in Streptozotocininduced diabetic rats," PLoS One, vol. 11, no. 1, article e0146438, 2016.

[49] L. Zhu, J. Han, R. Yuan, L. Xue, and W. Pang, "Berberine ameliorates diabetic nephropathy by inhibiting TLR4/NF- $\kappa$ B pathway," Biological Research, vol. 51, no. 1, 2018.

[50] B. S. Karam, A. Chavez-Moreno, W. Koh, J. G. Akar, and F. G. Akar, "Oxidative stress and inflammation as central mediators of atrial fibrillation in obesity and diabetes," Cardiovascular Diabetology, vol. 16, no. 1, 2017.

[51] O. M. Ighodaro, "Molecular pathways associated with oxidative stress in diabetes mellitus," Biomedicine \& Pharmacotherapy, vol. 108, pp. 656-662, 2018.

[52] K. Rehman and M. S. H. Akash, "Mechanism of generation of oxidative stress and pathophysiology of type 2 diabetes mellitus: how are they interlinked?," Journal of Cellular Biochemistry, vol. 118, no. 11, pp. 3577-3585, 2017.

[53] C. Poblete-Aro, J. Russell-Guzmán, P. Parra et al., "Exercise and oxidative stress in type 2 diabetes mellitus," Revista Médica de Chile, vol. 146, no. 3, pp. 362-372, 2018.

[54] E. Nozik-Grayck, H. B. Suliman, and C. A. Piantadosi, "Extracellular superoxide dismutase," The International Journal of Biochemistry \& Cell Biology, vol. 37, no. 12, pp. 2466-2471, 2005.

[55] C. Song, L. Sheng, and X. Zhang, "Preparation and characterization of a thermostable enzyme (Mn-SOD) immobilized on 
supermagnetic nanoparticles," Applied Microbiology and Biotechnology, vol. 96, no. 1, pp. 123-132, 2012.

[56] D. Tsikas, "Assessment of lipid peroxidation by measuring malondialdehyde (MDA) and relatives in biological samples: analytical and biological challenges," Analytical Biochemistry, vol. 524, pp. 13-30, 2017.

[57] D. A. Slatter, C. H. Bolton, and A. J. Bailey, "The importance of lipid-derived malondialdehyde in diabetes mellitus," Diabetologia, vol. 43, no. 5, pp. 550-557, 2000. 